\title{
EFEITO ANTIFÚNGICO DE EXTRATOS ALCOÓLICOS DE PRÓPOLIS SOBRE PATÓGENOS DA VIDEIRA*
}

\section{Marini, R. Mensch, M.B. Freiberger, J. Dartora, G. Franzener, R.C. Garcia, J.R. Stangarlin}

Universidade Estadual do Oeste do Paraná, CP 91, CEP 85960-000, Marechal Cândido Rondon, PR, Brasil. E-mail: denielemarini@yahoo.com.br

\section{RESUMO}

\begin{abstract}
Objetivou-se com este trabalho verificar a fungitoxicidade in vitro de extratos alcoólicos de própolis (EAP) sobre a germinação de esporos de Phakopsora euvitis e Pseudocercospora vitis e também sobre o crescimento micelial e esporulação de esporos de Elsinoe ampelina. Para o ensaio de inibição de germinação o EAP foi utilizado nas concentrações de 0,025; 0,05;0,1;0,2;0,25 e 0,5\%. Como testemunhas utilizaram-se água destilada, etanol $0,35 \%$ e fungicida azoxystrobin. No ensaio de crescimento micelial e esporulação foram utilizadas as concentrações de 0,$05 ; 0,1 ; 0,2 ; 0,4 ; 0,5$ e $1,0 \%$ de EAP. As testemunhas foram o meio de cultura batata-dextrose-ágar (BDA), BDA + 0,7\% de etanol e o fungicida azoxystrobin. Os resultados obtidos permitiram concluir que o EAP possui baixa atividade antifúngica in vitro contra $P$. euvitis, $P$. vitis e E. ampelina, para as concentrações testadas.
\end{abstract}

PALAVRAS-CHAVE: Phakopsora euvitis, Pseudocercospora vitis, Elsinoe ampelina.

\section{ABSTRACT}

ANTIFUNGAL EFFECT OF PROPOLIS ALCOHOLIC EXTRACTS ON GRAPEVINE PATHOGENS. The objective of this work was to verify the in vitro effect of alcoholic extracts of propolis (AEP) on the germination of spores of Phakopsora euvitis and Pseudocercospora vitis, and also on the mycelial growth and sporulation of Elsinoe ampelina. For the germination assay the AEP was used at concentrations of $0.025 ; 0.05 ; 0.1 ; 0.2 ; 0.25$ and $0.5 \%$. Distilled water, ethanol at $0.35 \%$ and the fungicide azoxystrobin were used as control treatments. For mycelial growth and sporulation the concentrations $0.05 ; 0.1 ; 0.2 ; 0.4 ; 0.5$ and $1.0 \%$ of AEP were used. The control treatments were potato-dextrose-agar (PDA) medium, PDA $+0.7 \%$ ethanol and the fungicide azoxystrobin. The results showed that $\mathrm{AEP}$ has a low in vitro antifungal activity against $P$. euvitis, $P$. vitis and $E$. ampelina, for the tested concentrations.

KEY WORDS: Phakopsora euvitis, Pseudocercospora vitis, Elsinoe ampelina.

Entre as frutíferas cultivadas no Brasil, a videira é uma das mais importantes no aspecto econômico e social. Na uva, sobretudo a destinada a consumo in natura, a qualidade fitossanitária é de suma importância. As doenças que incidem sobre esta cultura reduzem a qualidade e produtividade dos frutos, além de promoverem a elevação dos custos de produção, sendo, em sua maioria, causadas por fungos que afetam a parte aérea das plantas, causando doenças como míldio, escoriose, oídio, antracnose, mancha da folha eferrugem (AMORIM; KUNIYUKI, 2005).

A ferrugem é causada por Phakopsora euvitis Ono, a mancha da folha por Pseudocercospora vitis (Berk \& Curtis) Sacc. e a antracnose por Elsione ampelina (De Bary) Shear (Gallotтi et al., 2002). O controle dessas doenças tem sido feito principalmente por meio da utilização de defensivos agrícolas. No entanto, o uso intensivo eindiscriminado de fungicidas sistêmicos a longo prazo tem causado diversos problemas, como a seleção de patógenos resistentes aos princípios ativos mais utilizados, além de aspectos negativos para o ambiente, em função da poluição causada pelos resíduos (SCHWAN-Estrada; STANGARLIN, 2005).

Uma alternativa ao uso de agrotóxicos é o emprego do manejo integrado das doenças de plantas com foco agroecológico, o qual inclui o controle biológico, o controle cultural, o emprego de cultivares resistentes e o uso de produtos naturais com atividade indutora de resistência e/ou com atividade antimicrobiana direta. Nestaúltima forma decontrole encaixa-se o uso de extratos vegetais e microbianos em plantas (STANGARLIN et al., 2008).

A própolis é uma resina produzida por abelhas melíferasa partir desubstâncias coletadas em diferentes partes das plantas (BuRDOCK, 1998). A composição da própolis é extremamente complexa, com mais de 300

*Programa de Pós-graduação em Agronomia. 
substâncias diferentes já identificadas (BANKOVA et al., 2000). Na literatura é relatada como uma substância composta deóleos voláteiseácidosaromáticos (5a10\%), ceras (30-40\%), resinas, bálsamos, pólen e elementos essenciais como magnésio, níquel, cálcio, ferro e zinco, além de flavonoides, ácidos fenólicos, ésteres, aldeídos fenólicosecetonas, consideradosimportantescompostos antimicrobianos (WIESE, 1995; CASTALDO; CAPASSO, 2002).

Os estudos sobre as propriedades antibióticas da própolis têm sido conduzidos, sobretudo na área médica e veterinária, porém, segundo BIANCHINI; BEDENDO (1998), bactérias fitopatogênicas como Agrobacterium tumefaciens, Xanthomonas axonopodis pv. phaseoli e Erwinia chrysanthemi são sensíveis às substâncias antibióticas presentes na própolis. No entanto, pouco se conhece sobre seus efeitos contra fungos fitopatogênicos. Assim, objetivou-se com este trabalho verificar a fungitoxidade in vitro de extratos alcoólicos de própolis sobre os patógenos da videira P. euvitis, P. vitis e E. ampelina.

Os ensaios foram realizados no mês de novembro e dezembro de 2007 no Laboratório de Fitopatologia da Universidade Estadual do Oeste do Paraná. Os uredósporos de $P$. euvitis e conídios de $P$. vitis foram removidos de folhas frescas, enquanto os esporos de E. ampelina foram obtidos a partir de frutos das plantas apresentando sintomas característicos da doença.

A própolis na sua forma bruta foi obtida de colmeias de Apis melliphera, da região Oeste do Paraná. As amostras de própolis foram trituradas em liquidificador e, posteriormente, preparou-se o extrato alcoólico de própolis (EAP), utilizando a proporção de $15 \mathrm{~g}$ de própolis para $35 \mathrm{~mL}$ de álcool etílico a $70 \%$. O extrato permaneceu ao abrigo da luz, sendo agitado manualmente por 1 minuto duas vezes ao dia. Após 7 dias, ele foi filtrado em papel Whatman

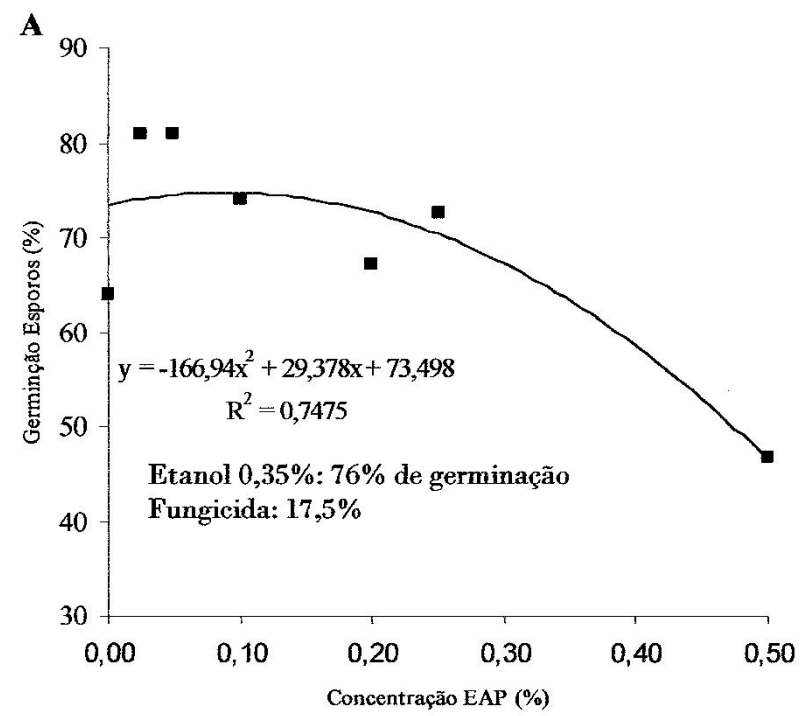

$\mathrm{n}^{\mathrm{o}} 1$ (GARCia et al., 2004).

Para o ensaio deinibição de germinação deesporos de P. euvitis e $P$. vitis foram utilizadas as concentrações 0,025; 0,05; 0,1; 0,2; 0,25 e 0,5\% de EAP diluídas em água destilada esterilizada. Como testemunhas utilizaram-se: água destilada; etanol a $0,35 \%$; e fungicida azoxystrobin $\left(0,08 \mathrm{~g}\right.$ i. a. $\left.\mathrm{L}^{-1}\right)$. O ensaio foi realizado em lâmina de microscopia revestida por água-ágar a $2 \%$, as quais foram incubadas no escuro a $25^{\circ} \mathrm{C}$ sobre a bancada dolaboratório por 18h (FRANZENERetal., 2003). Ao final do ensaio foram avaliados a porcentagem de germinação de esporos e o tamanho dos tubos germinativos de $P$. euvitis e $P$. vitis.

Para o ensaio de inibição do crescimento micelial e da esporulação de E. ampelina foram utilizadas as concentrações de 0,$05 ; 0,1 ; 0,2 ; 0,4 ; 0,5$ e 1,0\% de EAP diluídas com caldo de batata (STANGARLIN et al., 1999). As testemunhas foram: o meio de cultura batata-dextrose-ágar(BDA); BDA + etanol 0,7\%; eo fungicida azoxystrobin $\left(0,08\right.$ gi.a. $\left.\mathrm{L}^{-1}\right)$. As placas dePetricontendo micélio de E. ampelina foram mantidas em ambiente climatizado a $25^{\circ} \mathrm{C}$, com fotoperíodo de 16 horas, por 7 dias. A esporulação foi avaliada após o término da avaliação do crescimento micelial, com auxílio de uma câmara de Neubauer ao microscópio ótico conforme metodologia descrita por FRANZENER et al. (2006).

O delineamento experimental utilizado foi inteiramente casualizado com quatro repetições. Após a análise de variância e, no caso de haver significância $(\mathrm{P}<0,05)$, os fatores qualitativos foram comparados pelo teste de Tukey $(\mathrm{P}<0,05)$, enquanto os fatores quantitativos foram submetidos à análise de regressão polinomial. Dados em percentagem foram submetidos à transformação por raiz quadrada de $x+0,5$. Utilizou-se o programa estatístico SISVAR para processamento dos dados.

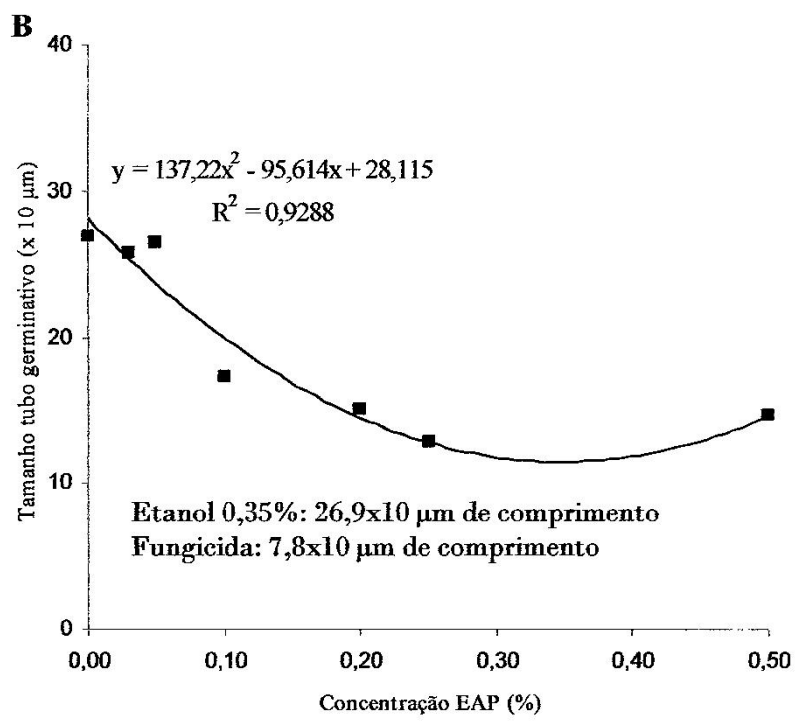

Fig. 1 - Germinação (A) e tamanho de tubo germinativo (B) de esporos de Phakopsora euvitis em presença de diferentes concentrações de extrato alcoólico de própolis (EAP). 
Para germinação de esporos de P. euvitis (Fig. 1A) houve ajuste de um modelo de regressão quadrática $\left(R^{2}=0,75\right)$, com efeito dose-dependente evalor médio de inibição de $30,4 \%$. Houve redução da germinação de $P$. euvitis para a concentração $0,5 \%$ de EAP. Para a avaliação de tamanho de tubo germinativo dos esporos (Fig. 1B) observou-se um modelo de regressão quadrática $\left(R^{2}=0,92\right)$, também apresentando efeito dose-dependente, com a concentração de própolis de maior eficiência ao redor de $0,35 \%$.

No ensaio de inibição de germinação de esporos de $P$. vitis (Tabela 1 ), não se observaram diferenças significativas entre as concentrações de EAP e as testemunhas, exceto para o fungicida, que foi capaz de reduzir em apenas $15 \%$ a germinação de conídios desse fungo, dessa forma, não foi possível ajuste de nenhuma equação na regressão dos dados. Já para o ensaio de tamanho de tubo germinativo observa-se ajuste de um modelo de regressão linear $\left(R^{2}=0,74\right)$, que permite observar que mesmo não inibindo a germinação, o EAP na concentração de $0,5 \%$ reduziu o comprimento do tubo de P. vitis (Fig. 2).

A análise das médias dos tratamentos no ensaio de esporulação de E. ampelina demonstrou que o fungicida e a concentração de $0,5 \%$ de EAP apresentaram tendência de serem mais eficientes, porém, semelhantes às outras concentrações de EAP e à testemunha meio BDA + 0,7\% de etanol (Tabela 2). A regressão para as concentrações de EAP não foi significativa, no entanto, o teste de médias mostra que o EAP tem efeito inibitório na esporulação, assim como o etanol. Para o ensaio de inibição de crescimento micelial (Fig. 3), observa-se um modelo de regressão linear $\left(R^{2}=0,86\right)$, onde o aumento das concentrações de EAP resultou em menor diâmetro das colônias de E. ampelina.

$\mathrm{Na}$ literatura encontram-se poucos trabalhos utilizando própolis em vegetais, principalmente para controle de doenças fúngicas. Piermann et

Tabela 1 - Efeito in vitro de extrato alcoólico de própolis sobre a germinação de esporos de Pseudocercospora vitis.

\begin{tabular}{lc}
\hline Tratamentos & Germinação (\%) \\
\hline Água & $96,00 \mathrm{~b}^{* *}$ \\
Etanol 0,35\% & $95,25 \mathrm{~b}$ \\
Fungicida (azoxystrobin 0,08 gi.a. $\mathrm{L}^{-1}$ ) & $80,75 \mathrm{a}$ \\
Extrato alcoólico de própolis* & $96,87 \mathrm{~b}$ \\
\hline *Média de todas as concentrações testadas; \\
**Médias seguidas de mesma letra não diferem entre si \\
pelo teste de Tukey a 5\% de probabilidade.
\end{tabular}

al. (2007) testaram extrato de própolis obtido de produto comercial na concentração de $10 \%$ em oito diferentes fitobactérias: Pseudomonas syringae pv. tomato, P. corrugata, Clavibacter michiganensis subsp. michiganensis, Erwinia carotovora subsp. carotovora, Xanthomonas campestris pv. vesicatoria, X. translucens pv. undulosa, X. axonopodis pv. phaseoli $X$. campestris pv. campestris. Esses autores conseguiram inibir de forma acentuada a multiplicação das bactérias em estudo, ao contrário do que ocorreu neste trabalho com os fungos da videira, embora as concentrações de própolis aqui testadas tenham sido entre 10 e 20 vezes menores.

BIANCHINI; BEDENDO (1998) também estudaram o efeito antibiótico de extrato aquoso de própolis, nas concentrações de 0,1, 1,0 e 10\%, sobre cinco espécies de bactérias fitopatogênicas, e demostraram que três espécies foram completamente inibidas em meio de cultura contendo $10 \%$ de extrato de própolis. Novamente, as maiores inibições ocorreram com elevadas concentrações de extrato de própolis. No presente estudo, as atividades antifúngicas não foram tão expressivas para as concentrações testadas, pois estas foram relativamente baixas já que em condições de campo normalmente se utilizam concentrações abaixo de $1 \%$, para evitar problemas de fitotoxicidade.

Albano et al. (2007), em ensaio com sementes de feijão tratadas com extrato de borra de própolis a $25 \%, 50 \%, 75 \%$ e $100 \%$, observaram inibição de patógenos comuns ao processo de armazenamento, tal efeito antifúngico dose-dependente coincide com o verificado neste trabalho.

Pode-se concluir com este trabalho que o EAP possui atividade antifúngica in vitro, embora baixa para as concentrações testadas, contra $P$. euvitis, $P$. vitis e E. ampelina. A fungitoxidade do EAP pode ser verificada na inibição de germinação de esporos, na tendência em reduzir o tamanho dos tubos germinativos e na inibição de crescimento micelial, de maneira dose-dependente.

Tabela 2 - Efeito de extrato alcoólico de própolis na esporulação in vitro de Elsinoe ampelina.

\begin{tabular}{lc}
\hline Tratamentos & $\begin{array}{c}\text { Esporulação } \\
\text { (esporos } \times 10^{4} \mathrm{~mL}^{-1} \text { ) }\end{array}$ \\
\hline Meio BDA & $181,95 \mathrm{~b}^{* *}$ \\
Meio BDA + 0,7\% de etanol & $70,61 \mathrm{ab}$ \\
Fungicida(azoxystrobin0,08gi.a. $\mathrm{L}^{-1}$ ) & $1,15 \mathrm{a}$ \\
Extrato alcoólico de própolis* & $30,68 \mathrm{ab}$ \\
Extrato alcoólico de própolis 0,5\% & $10,84 \mathrm{a}$ \\
${ }^{*}$ Média de todas as concentrações; \\
**Médias seguidas de mesma letra não diferem entre si \\
pelo teste de Tukey a 5\% de probabilidade.
\end{tabular}




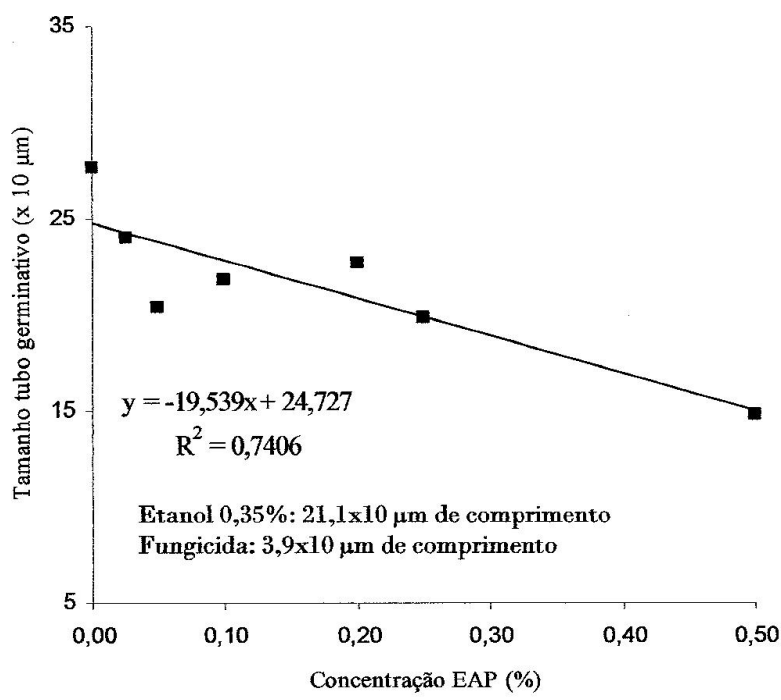

Fig. 2 - Tamanho médio de tubo germinativo de esporos de Pseudocercospora vitis em presença de diferentes concentrações de extrato alcoólico de própolis (EAP).

\section{REFERÊNCIAS}

ALBANO, E.M.S.; ZAINA, T.C.; ZANIN, D.G.; GONÇALVES, R.A. Avaliação da ação do extrato da borra da própolis no controle de sanidade de sementes de feijão. Fitopatologia Brasileira, v.32, p.147, 2007. Suplemento.

AMORIM, L.; KUNIYUKI, H. Doenças da videira. In: KIMATI, H.; AMORIM, L.; BERGAMIM FILHO, A.; CAMARGO, L.E.A.; REZENDE, J.A (Ed.). Manual de Fitopatologia: doenças das plantas cultivadas. São Paulo: Ceres, 2005. p.639-651.

BANKOVA, V.S.; CASTRO, S.L.; MARCUCCI, M.C. Propolis: recent advances in chemistry and plant origin. Apidologie, v.31, p.3-15, 2000.

BIANCHINI, L.; BEDENDO, I.P. Efeito antibiótico do própolis sobre bactérias fitopatogênicas. Scientia Agrícola, v.55, p.149-152, 1998.

BURDOCK, G.A. Review of the biological properties and toxicity of bee propolis (propolis). Food and Chemical Toxicology, v.36, n.4, p.347-363, 1998.

CASTALDO, S.; CAPASSO, F. Propolis, an old remedy used in modern medicine. Fitoterapia, v.73, p.S1-S6, 2002. Supplement 1.

FRANZENER, G.; STANGARLIN, J.R.; SCHWAN-ESTRADA, K.R.F.; CRUZ, M.E.S. Atividade antifúngica e indução de resistência em trigo a Bipolaris sorokiniana por Artemisia camphorata. Acta Scientiarum Agronomy, v.25, n.2, p.503-507, 2003.

FRANZENER, G.; FRANZENER, A.S.M.; STANGARLIN, J.R.; CZEPAK, M.P.; SCHWA-NESTRADA, K.R.F.; CRUZ, M.E.S. Atividades antibacteriana, antifúngica e indutora de fitoalexinas de hidrolatos de plantas medicinais. Semina Ciências Agrárias, v. 28, p.29-38, 2006.

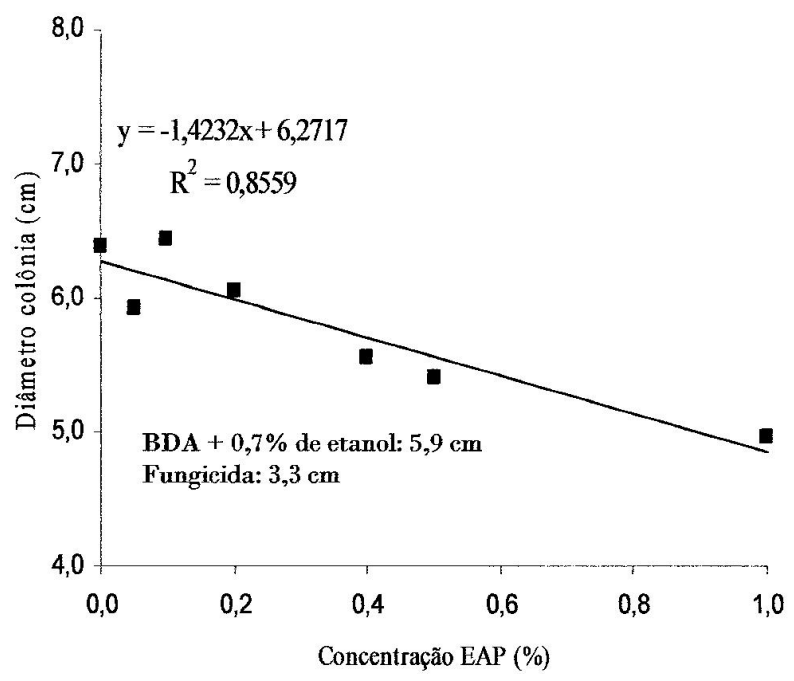

Fig. 3 - Crescimento micelial de Elsinoe ampelina em presença de diferentes concentrações de extrato alcoólico de própolis (EAP).

GALLOTTI, G.J.M.; GRIGOLETTI JÚNIOR, A.; SONEGO, O.R. Controle das doenças da videira. In: ZAMBOLIM, L.; VALE, F.X.R.; MONTEIRO, A.J.A.; COSTA, H. (Ed.). Controle de doenças de plantas: fruteiras. Viçosa: os editores, 2002. p.939-1022.

GARCIA R.C., SÁ M.E.P., LANGONI H. \& FUNARI S.R.C. Efeito do extrato alcoólico de própolis sobre a Pasteurella multocida "in vitro". Acta Scientiarum, Animal Sciece, v.26, n.1, p.69-77, 2004.

PIERMANN, L.; SILVA, I.T. da; OLIVEIRA, J.R.; FUJINAWA, M.F.; LIMA, H.E. de; PONTES, N. de C. Efeito de extratos vegetais e própolis sobre o crescimento in vitro de fitobactérias. Fitopatologia Brasileira, v.32, p.156, 2007. Suplemento

SCHWAN-ESTRADA, K.R.F.; STANGARLIN, J.R. Extratos e óleos essenciais de plantas medicinais na indução de resistência. In: CAVALCANTI, L.S.; DI PIERO, R.M.; CIA, P.; PASCHOLATI, S.F.; RESENDE. M.L.V.; ROMEIRO, R.S. (Ed.). Indução de resistência em plantas a patógenos e insetos. Piracicaba: FEALQ, 2005. p.125-133.

STANGARLIN, J.R.; SCHWAN-ESTRADA, K.R.F.; CRUZ, M.E.S.; NOZAKI, M.H. Plantas medicinais e controle alternativo de fitopatógenos. Biotecnologia Ciência \& Desenvolvimento, v.2, n.11, p.16-21, 1999.

STANGARLIN, J.R.; KUHN, O.J.; SCHWAN-ESTRADA, K.R.F. Controle de doenças de plantas por extratos de origem vegetal. Revisão Anual de Patologia de Plantas, v.16, p.265-304, 2008.

WIESE, H. Novo Manual de apicultura. Guaíba: Agropecuária, 1995. p.291

Recebido em 25/5/11

Aceito em 6/12/11 